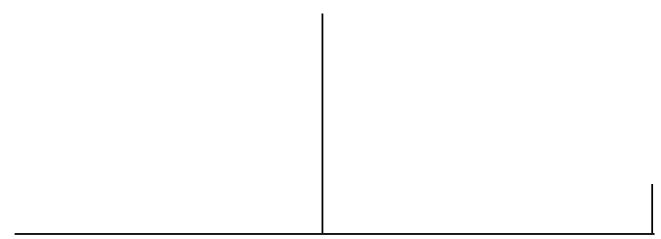

Rev. Latinoam. Psicopat. Fund., São Paulo, v. 15, n. 4, 881-890, dezembro 2012

\title{
Transitoriedade ou o desterro da certeza*
}

\author{
Paulo José Carvalho da Silva
}

O tema da transitoriedade era lugar-comum da medicina da alma da primeira modernidade. Este artigo analisa algumas dessas fontes para mostrar como a dor do tempo e os males da alma atinentes eram relacionados a um modo de encarar a fugacidade do tempo e a fragilidade da vida. Dá-se destaque, sobretudo, às construções em torno da condição humana enquanto desterro da certeza.

Palavras-chave: Transitoriedade, desterro da certeza, males da alma, dor do tempo

* Pesquisa realizada com apoio do Conselho Nacional de Desenvolvimento Científico e Tecnológico - CNPq (Brasília, DF, Br) (Bolsa de produtividade em Pesquisa). 
Em "A transitoriedade", de 1916, Freud afirma que a exigência de perenidade da beleza da natureza e das criações da civilização é um produto dos desejos humanos. Freud procura consolar o pessimista poeta, que ressente a transitoriedade do belo a ponto de não poder fruir da paisagem da bela estação, antecipando sua desaparição invernal, e enfatiza que o valor de transitoriedade é valor de raridade no tempo, isto é, a brevidade não desvaloriza, pelo contrário, acrescenta encanto. Ele conclui, entretanto, que há uma dificuldade de ordem emocional, mais precisamente, uma revolta psíquica contra o luto, cujo gosto de ruína futura pode contaminar o gozo presente. Como o desprendimento da libido de seus objetos é fonte de dor, algumas almas mais sensíveis não são capazes da renúncia permanente exigida na fruição de tudo que é precário e transitório, mesmo no que há de mais sublime e precioso.

Tal reflexão teve como contexto a Primeira Guerra Mundial que, segundo o próprio Freud, mostrou a vida pulsional em toda sua crueza, despertou os piores espíritos, despojou a muitos do que mais amavam e revelou a fragilidade do que se supunha sólido. Não é à toa, sua atenção, neste período, às paixões tristes, em especial, à psicopatologia do luto.

É sabido que a virada para a Idade Moderna também suscitou reflexões sobre a precariedade do humano e os males da alma, como o próprio desamparo e a melancolia. Georges Minois (2003) lembra que o chamado espírito moderno ao mesmo tempo em que reivindicava sua autonomia, confrontava-se com sua solidão no universo. As pessoas dos séculos XVI e XVII viviam num mundo de dimensões nunca antes imaginadas, descentralizado, violento, conturbado e confuso. Novas filosofias, novas religiões, novos territórios e povos fazem o homem moderno questionar antigas certezas sobre os limites do mundo e os destinos da alma humana. 
Jean Rouhou (2002) descreve claramente que quando ainda parecia reinar a ordem, encarnada no regime absolutista e na supremacia da religião, emergia uma subjetividade inquieta, atravessada por uma crise dos fundamentos cosmológicos, teológicos e filosóficos. Esta crise é o fermento da civilização moderna, razão de uma outra relação com a natureza, com o próprio homem e com a ideia do que permanece. A própria transição para o mundo da felicidade individual, cujo critério é a utilidade e a rentabilidade, o agente é o indivíduo e não o coletivo hierarquicamente organizado, e a racionalidade não serve mais para se inscrever na ordem do cosmos, mas como método puro, usado para manipular a natureza em nome da eficiência, revela o quão a estabilidade e a unidade sólida não passam de projeções magnificantes da precária condição humana.

Nesse momento instável e duvidoso, enfatizava-se o quanto, para o ser humano, toda esperança de estabilidade seria uma ilusão. Tema onipresente nos escritos examinados numa investigação mais ampla sobre os males da alma do homem moderno, da qual resulta este artigo que, ao final, mostrará como os discursos sobre a transcendência da transitoriedade revelam tentativas de consolação no desterro da certeza.

\section{Cogita fugam temporis}

Na Antiguidade, autores como Horácio, Virgilio e Sêneca meditaram sobre o tema da fugacidade do tempo. Já na primeiríssima modernidade, o mote torna-se recorrente na produção do humanista italiano Francesco Petrarca (13041374). Retomando o De brevitate vitae de Sêneca, Petrarca enfatiza não apenas a brevidade da vida humana, mas evoca, em especial, a fuga do tempo enquanto algo que não se pode expressar em palavras. Ou ainda, no Secretum, escreve: "Pense na morte que é certíssima, e na sua hora que é dúbia" (Petrarca, 2000, p. 279). Por isso, desapegado da esperança da vida longa, dever-se-ia viver cada dia como o derradeiro, pois, como sentencia o poeta: "toda a vida humana, por mais longa que seja, é semelhante a um só dia, e nem mesmo inteiro" (p. 313).

Alberto Tenenti (1983), ao examinar o sentido da duração em diferentes discursos da medicina da alma renascentista, reforça que as reflexões sobre a fugacidade da vida mundana inseriam-se nas múltiplas interpretações que o humanismo produziu sobre a defasagem entre o transitório e o eterno, em especial, no modo como ela se exprime na dinâmica entre o sentimento físico do tempo, ossatura da existência terrestre, e a fé na vida celeste. Entre a afirmação do direito à autonomia da vida deste mundo e a sua orientação pensando-se no destino eterno, o homem moderno interroga-se sobre as implicações do sentimento 
do correr do tempo e da incerteza da hora da morte no modo como se goza o presente. A obra em que o místico domenicano Henrique Suso (1295-1366) insiste que cada hora, cada dia, cada semana deve ser vivida como sendo a véspera da eternidade chama-se, justamente, Horlogium Sapientiae, isto é, Relógio da sabedoria, também conhecido como Livro da eterna sabedoria. É claro que a ideia da extinção física impactava de uma certa maneira porque o homem ainda estava seriamente comprometido com a questão da salvação da alma. De qualquer forma, parece permanecer que a lembrança da morte tem o poder de perturbar a apreciação do tempo.

A literatura luso-brasileira do período moderno oferece diferentes gêneros de discursos, também entendidos como variações de práticas de tratamento dos males da alma que, de alguma forma, desenvolvem o topos da transitoriedade. A inconstância e a brevidade da vida neste mundo podiam se tornar argumentos para duas posturas opostas. De um lado, um hedonismo inconsequente e presentista. De outro, uma supervalorização do eterno, a esperar no mundo além-túmulo. De qualquer modo, esta vida seria um desterro da certeza, ou como escreve Luís de Camões (1524-1580): “Ao seu fim todas cousas vão correndo;/Nem há cousa que o tempo não consuma (...) Que o mais certo que temos/É não termos nada certo/Cá na terra,/Pois pera seus não nascemos;/Se o seu nos dá incerto,/Nada erra" (Camões, 2005, p. 783).

Raymond Baustert (2003) avalia que na literatura europeia, do período conhecido como Barroco, o antigo tema da fragilidade e do efêmero torna-se ainda mais presente, por meio de imagens bem ao gosto da época, como a da vida como neve ao sol ou como areia movediça ou ainda, dentro das metáforas botânicas, do corpo como botão de rosa que mal abre e já desvanece e da própria vida como um roseiral ao vento.

Em Alívio de tristes e consolação de queixosos, do teólogo Mateus Ribeiro, são evidenciadas as atribulações da vida em sociedade, em especial, nas cortes de norte a sul da Europa: traições, guerras, falências, desterros e catástrofes naturais seriam os sinais de que mesmo nos recantos mais faustosos deste mundo não há felicidade sólida. O próprio autor indica a fonte antiga da máxima tão apropriada à apreciação da existência moderna: "Brevissima duração attribui Cicero aos contentamentos da vida, como a agoa que corre, como o vento que voa" (Ribeiro, 1648 , p. 80).

Já vimos que, naquela época, vivia-se sob a sombra da enfermidade (Carvalho da Silva, 2012), o que também remete ao tema do transitório radical. Para dar mais um exemplo de como esse lugar-comum era especificamente aplicado à arte de orientar, aconselhar e consolar aquele que sofre dos sinais da corrupção inevitável do corpo vivo, vale citar que o jesuíta português Estevão Castro (1575- 
-1639) insiste que o enfermo deve estar persuadido de que sua condição de vivente é a de um peregrino no desterro: "E assim havemos de passar pelo mundo, como por caminho sem nos determos, \& não devemos parar nos bens da vida, cuydando ter aqui firmeza de morada paterna (o que seria falso, porque na verdade não na ha nas cousas da terra)" (Castro, 1723, p. 197).

O mesmo aparece nas homenagens prestadas aos mortos, que são, no fundo, mensagens aos viventes. Frei Fernando de Santo Augustinho, em sua Oraçam fúnebre nas Exequias annuaes do Serenissimo rei de Portugal Dom Manuel de gloriosa memória, de 1685, resume a função desse discurso que rememora a perda: ele serve para renovar os laços afetivos com o soberano desaparecido ao mesmo tempo em que funciona como aviso edificante sobre a precariedade da vida neste mundo. Para o frei, bem como para tantos autores do período, o próprio cerimonial fúnebre prega: "a brevidade da vida, o desengano do tempo, \& a certeza da morte" (de Santo Augustinho, 1685, p. 5).

\section{Sob o céu da incerteza}

A condição de desterro está relacionada à constatação de que as promessas desse mundo são todas falsas, porque nada nele sustenta-se em si mesmo, sendo, portanto, o território da inconstância. Ou como afirma o jesuíta Alexandre de Gusmão (1649-1724), na História do Predestinado Peregrino e seu Irmão Precito: "O mundo tudo he nada, ou ao revès, nada é tudo o do mundo" (1685, p. 25). Isto é, entre tantos outros autores do período, Gusmão repete insistentemente que esse mundo tão estimado não passa de uma sombra que desaparece, um fumo que cega a vista. Quando experimenta os óculos do espírito, o protagonista "Predestinado Peregrino" pode ver o mundo como realmente é: "Este he o mundo (...) nenhuma outra couza he, senam huma bicha de sete cabeças, ou uma Chimera, que não tem ser, mais que o fingido, que a fantezia dos homens lhe considera" (Gusmão, 1685, p. 46).

O padre Nuno Marques Pereira (1652-1728), no Compêndio Narrativo do Peregrino da América, por sua vez, frisa o caráter inconstante do próprio homem: "E assim não há no homem firmeza, nem estabilidade, que por muito tempo dure, por andar sempre em huma perpetua mudança" (Pereira, 1760, p. 6).

Como resume Alcir Pécora (1994), a essência do engaño barroco consiste no atribuir eternidade ao temporal, estabilidade ao provisório, substância ao ser que, na contingência, é, sobretudo, analogia. Por isso, ao desmascaramento da inverdade das aparências e à renúncia da ilusão de autonomia e independência, dava-se o nome de desengano. Para desenganar-se é necessário, nas palavras de 
Gusmão: "considerar as delicias desta vida como couzas, que vam \& nam como couzas que vem; de passagem, \& nam de assento" (1685, p. 189). Não é sem razão que em sua novela alegórica o personagem desengano é casado com a verdade.

O tema da dor do tempo aparece também na produção poética barroca de língua portuguesa. O soneto A fragilidade da vida humana de Francisco de Vasconcelos (1665-1723) reúne todos os elementos da ânsia moderna; desde a ruína antecipada na flor murcha até o encobrimento da verdade pelo véu das vãs aparências e falsas riquezas, sem deixar de mencionar que até as estrelas, antes supostas norte certo pois em trajetórias fixas, agora também enganam:

Baixel de confusão em mares de ânsia,/Edifício caduco em vil terreno,/Rosa murchada já no campo ameno,/Berço trocado em tumba desd'a infância,/Fraqueza sustentada em arrogância,/Néctar suave em campo de veneno,/Escura noite em lúcido sereno,/Sereia alegre em triste consonância,/Viração lisonjeira em vento forte,/Riqueza falsa em venturosa mina,/Estrela errante em fementido norte,/Verdade que o engano contamina,/Triunfo do temor, troféu da morte/É nossa vida vã, nossa ruína. (Vasconcelos, in: Pécora, 2002, p. 154)

A precariedade das coisas terrestres também é posta em versos pelos reformados. O pastor calvinista Antoine de la Roche-Chandieu (1534-1591) retoma o tema, várias vezes, em Octonaires sur la Vanité et Inconstance du Monde. Exemplo:

XXVIII. A beleza do mundo se apaga/De repente, como um vento que passa,/De repente, como se vê a flor/Sem sua primeira cor,/De repente, como uma onda foge/frente a outra que a segue./O que é então o mundo? Um vento, uma flor, uma onda. (Chandieu, 1583/1979, p. 71, trad. nossa)

É preciso advertir, porém, que afirmar a brevidade da vida terrena não significava necessariamente negá-la, precipitando-se no gozo do absoluto que só a morte poderia prometer. Não que isso não fosse cogitado, por isso mesmo combatido. Em um de seus sermões, o padre Antonio Vieira (1608-1696) contrapõe à escolha de uma morte imediata mas certa da salvação, que ele supõe afeita à atitude intelectual de Diogo Laines, um dos primeiros jesuítas, o exercício ativo proposto por Inácio de Loyola, para o qual a ação no mundo terreno deveria se sustentar no desejo, mesmo que na incerteza:

Laines, com todas as suas lettras disse, que em similhante caso, se a eleição fosse sua, escolheria ir logo para o céo. Porém Sto Ignacio, com o heroico e sublime de seu espirito, respondeu, que antes elegeria ficar no mundo servindo a Deus na salvação dos proximos, ainda com incerteza do mesmo céo. (Vieira, s.d./ 1951, Vol. IX, p. 316) 
Assim, todos esses discursos sobre a transitoriedade podem até visar o desapego humano e o desprezo da vida mundana, mas raramente uma posição passiva e desesperada frente a suas aflições. Isso se confirma, sobretudo, nos discursos jesuíticos do período, pois, para eles, a mínima possibilidade de felicidade terrena residia na vida ativa, em movimento, como ilustra a imagem da existência enquanto passagem, ou mais precisamente, peregrinação no exílio da casa Paterna.

Uma vida não apenas ativa, mas sustentada no desejo, a despeito de qualquer promessa de duração, estabilidade e utilidade imediata. Para terminar mantendo-se no campo do simbolismo pastoral sobre o transitório, vale convocar mais um desterrado, um errante da mística alemã, cuja retomada da tradição do ohne Warum (sem porque) fascinara Heidegger e Lacan, sobretudo o dístico 289 do livro I do Cherubinischer Wandersmann (Viajante querubínico), onde Angelus Silesius (1624-1677) escreve: "A rosa não tem porquê; ela floresce porque floresce,/Não cuida de si mesma, nem pergunta se alguém a vê”' (Silesius, 2004, p. 126).

\section{Referências}

Baustert, R. (2003). La consolation érudite. Huit études sur les sources des lettres de consolation de 1600 à 1650. Tübingen: Guter Narr.

Camões, L. (2005). Obra Completa. Rio de Janeiro: Nova Aguilar.

Carvalho da Silva, P. J. (2012). Sob a sombra do patológico: sujeito e verdade no adoecer. Revista Latinoamericana de Psicopatologia Fundamental, XV(3), 540-548, set.

Castro, E (1723). Breve aparelho e modo facil para ajudar a bem morrer hum Christão. Com a recopilação da mateira de testamentos, \& penitencia, varias orações devotas, tiradas da Escritura Sagrada, \& do Ritual Romano. Lisboa: Oficina de Antônio Medroso Galeão.

Chandieu, A. R. (1979). Octonaires sur la Vanité et Inconstance du Monde. Texte établi, annoté et commenté par F. Bonali-Fiquet. Genève: Droz.

De Santo Augustinho, F. (1685). Oraçam fúnebre nas Exequias annuaes do Serenissimo rei de Portugal Dom Manuel de gloriosa memória (...). Lisboa: João Galvão.

Freud, S. (2010). A transitoriedade. Obras Completas (Vol. 12; P. C. de Souza, trad.). São Paulo: Companhia das Letras. (Trabalho original publicado em 1916)

Gusmão, A. (1685). História do Predestinado Peregrino e seu Irmão Precito. Em a qual 
de baxo de huma misterioza parábola se descreve o sucesso feliz, do que se há de salvar, \& infeliz sorte do que há de se condenar. Évora.

Minois, G. (2003). Histoire du mal de vivre. De la mélancolie à la dépression. Paris: Éditions de La Martinière.

Pécora, A. (1994). Teatro do Sacramento. A unidade teológico-retórico-política dos sermões de Antonio Vieira. São Paulo/Campinas: Edusp/Unicamp.

Pécora, A. (org.). (2002). Poesia Seiscentista. São Paulo: Hedra.

Pereira, N. M. (1760). Compêndio narrativo do Peregrino da América. Lisboa: Antonio Vicente da Silva.

Petrarca, F. (2000). Il mio segreto (Secretum). Edição bilingue latina-italiana por U. Doti. Milano: Biblioteca Universali Rizzoli.

Ribeiro, M. (1648). Alivio de tristes e consolação de queixosos. Lisboa: Manoel Da Sylva.

Rohou, J. (2002). Le XVIIe siècle, une révolution de la condition humaine. Paris: Seuil.

Silesius, A. (2004). Le voyageur chérubinique. Paris: Éditions Payot et Rivages.

Tenenti, A. (1983). Sens de la mort et amour de la vie. Renaissance en Italie et en France. Paris: L'Harmmatan-Serge Fleury.

Vieira, A. (1951). Sermões (vol. IX). Porto: Lello e Irmão.

\section{Resumos}

(Transitoriness or exile from certainty)

The theme of transitoriness was commonplace in medicine of the soul of early modernity. This article examines some of these sources to show how the pain of time and similar ailments of the soul were related to a way of dealing with the fleetingness of time and the fragility of life. The author underlines constructions of the human condition as exile from certainty.

Key words: Transience, exile from certainty, ailments of the soul, pain of time

(La fugacité ou l'exil de la certitude)

Le thème de la fugacité était un lieu commun de la médecine de l'âme de la première modernité. Cet article examine quelques-unes de ces sources pour montrer comment la douleur du temps et le maux de l'âme étaient liés à une façon d'envisager la nature éphémère du temps et la fragilité de la vie. Cet article met en relief les constructions liées à la condition humaine comprise comme exil de la certitude.

Mots clés: Fugacité, exil de la certitude, maux de l'âme, douleur du temps 
(La transitoriedad o el destierro de la certeza)

El tema de la transitoriedad era un lugar común en la medicina del alma durante la primera modernidad. Este artículo analiza algunas de esas fuentes para mostrar como el dolor del tiempo y los males del alma estaban relacionados a un modo de encarar la fugacidad del tiempo y la fragilidad de la vida. Se destaca sobretodo las construcciones en torno de la condición humana como destierro de la certeza.

Palabras clave: Tansitoriedad, destierro de la certeza, males del alma, dolor del tiempo

(Vergänglichkeit oder Exil aus der Gewissheit)

In der Medizin der Seele war das Thema der Vergänglichkeit ein gewöhnliches Thema während der Frühen Neuzeit. Dieser Artikel untersucht einige Quellen dieser Zeit, um zu zeigen, wie der Schmerz der Zeit und andere Seelenleiden verbunden waren, um auf eine Weise der Vergänglichkeit der Zeit und der Zerbrechlichkeit des Lebens zu begegnen. Die Betonung liegt auf den Vorstellungen rund um den menschlichen Zustand als ein Exil aus der Gewissheit.

Schlüsselwörter: Vergänglichkeit, Exil aus der Gewissheit, Seelenleiden, Schmerz der Zeit

Citação/Citation: Carvalho da Silva, P. J. (2012, dezembro). Transitoriedade ou o desterro da certeza. Revista Latinoamericana de Psicopatologia Fundamental, São Paulo, 15(4), 881-890.

Editor do artigo/Editor: Prof. Dr. Paulo José Carvalho da Silva

Recebido/Received: 25.10.2012 / 10.25.2012 Aceito/Accepted: 5.11.2012/ 11.5.2012

Copyright: () 2009 Associação Universitária de Pesquisa em Psicopatologia Fundamental/ University Association for Research in Fundamental Psychopathology. Este é um artigo de livre acesso, que permite uso irrestrito, distribuição e reprodução em qualquer meio, desde que o autor e a fonte sejam citados / This is an open-access article, which permits unrestricted use, distribution, and reproduction in any medium, provided the original author and source are credited.

Rev. Latinoam. Psicopat. Fund., São Paulo, v. 15, n. 4, p. 881-890, dezembro 2012 
Financiamento/Funding: Esta pesquisa é financiada pelo Conselho Nacional de Desenvolvimento Científico e Tecnológico - CNPq / This research is funded by the Conselho Nacional de Desenvolvimento Científico e Tecnológico - CNPq.

Conflito de interesses/Conflict of interest: $O$ autor declara que não há conflito de interesses / The author declares that has no conflict of interest.

\section{Paulo José Carvalho da Silva}

Psicólogo, psicanalista, mestre em História da Ciência pela Pontifícia Universidade Católica de São Paulo - PUC-SP; doutor em Psicologia pela Universidade de São Paulo - USP (São Paulo, SP, Br); professor doutor da Faculdade de Psicologia da PUC-SP (São Paulo, SP, Br); membro da Associação Universitária de Pesquisa em Psicopatologia Fundamental (São Paulo, $\mathrm{SP}, \mathrm{Br}$ ).

Rua Monte Alegre, 984

05015-901 São Paulo, SP, Brasil

Fone: (11) 99248-9202

e-mail: paulojcs@ hotmail.com 